\title{
Towards Equivalence of Reynolds Number as Analytical Tool for Analysis of Housing Price Dynamics
}

\author{
M. BEŁEJ ${ }^{a, *}$ AND S. KuleszA ${ }^{b}$ \\ ${ }^{a}$ University of Warmia and Mazury in Olsztyn, Department of Spatial Analysis and Real Estate \\ Market, ul. Prawocheńskiego 15, PL 10720 Olsztyn, Poland \\ ${ }^{b}$ University of Warmia and Mazury in Olsztyn, Faculty of Mathematics and Computer Science, \\ ul. Stoneczna 54, PL 10710 Olsztyn \\ Doi: $10.12693 /$ APhysPolA.138.83 \\ *e-mail: miroslaw.belej@uwm.edu.pl
}

\begin{abstract}
In hydrodynamics, the Reynolds number is used to establish the critical points between laminar (stable) and turbulent fluid dynamics. The essence of the presented research is the search for an analogy between the evolution of housing prices and hydrodynamic phenomena accompanying the movement of bodies in the incompressible fluid. The aim of the article is to develop an equivalent of the Reynolds number (eReHM) used in the hydrodynamics for its implementation for the housing price dynamics analysis. The time horizon of research (2001-2017) includes a period of rapid increases in housing prices in 2006-2007. The obtained values of the Reynolds number of equivalents for the housing market allow to determine critical points between the stable and unstable evolution of property prices.
\end{abstract}

topics: Reynolds number, turbulent dynamics, housing market

\section{Introduction}

The housing market is the fundamental areas of the national economy which significantly affect the level of social needs fulfillment, the pace of socio-economic processes, and the effectiveness of all development activities [1]. Also is an important element of wealth as well as the single biggest expenditure for a majority of households [2]. Housing property is a special type of commodity because is a spatially immobile, highly durable, highly expensive, multidimensionally heterogeneous and physically modifiable commodity [3]. The housing market activity is largely affected by the phenomenon of interaction between the variables describing the economic environment and the factors which characterize demand, supply and prices [4], with the phenomenon, according to Orenstein and Hamburg [5], exhibiting high variability in time and space.

The mechanistic concept of economic phenomena, which is the essence of mainstream economics, still remains the main theoretical way of describing the housing market. The mechanistic approach neglects the existence of complex economic systems that on the whole have properties different from those specific of the elements they are made of [6]. According to Unold [7], the mechanistic concept is an economic atomism where the individual irreversibly influences the collective. Such a vision of the world can be reduced to a statement that the whole is only a direct sum of its parts. In that sense, the cause-effect mechanistic concept of the housing market is based on the paradigm of linearity, general equilibrium theory and human rationality (homo oeconomicus). Linearity means proportional input-output dependence, and that the dynamic of a system can be reconstructed by summing up the effects of single causes acting on single components, which allows efficient causality to operate, equations to be solved, and predictive modeling. By focusing on systems in equilibrium, researchers implicitly accept that the number of possible states a system may attain is limited (and computable) and that search time following the onset of instability is short compared to "equilibrium" time [8]. In a traditional approach the housing market have been treated as a synonym for stability and safety. However, the traditional manner of understanding the housing markets was significantly redefined by the considerable intensification of the tendency of a close relation between that market and financial markets via the mortgage system and properly constructed financial instruments, which became apparent in the beginning of 20th century. These issues are presented in more detail in the works of: Acharya et al. [9], Ashton [10], Roubini and Mihm [11], Demyanyk and Van Hemert [12]. As a consequence, the global financial crisis occurred, sometimes known as the mortgage crisis, which significantly changed our perception of the housing market. It also directed large attention to non-classic economic theories [13-20], because mainstream economics was unable to explain the increasing instability of market structures. As a result of this 
work, six assumptions were made to perform a nonclassical analysis of economic systems [21]: dispersed interaction among heterogeneous agents, no global controller in the economy, cross-cutting hierarchies with tangled interactions, continual adaptation and learning by evolving agents, perpetual novelty and out-of-equilibrium dynamics with no presumption of optimality.

Presented work promotes methodological pluralism which is characterised by greater openness in search of alternative solutions while applying interdisciplinary research methods in the field of housing prices dynamics. Consequently, the authors fully accept that the multidimensionality of housing market requires the extension of mechanistic conception of general equilibrium and principles of determinism and reductionism, to be extended into interdisciplinary framework of multi-point dynamic balance, limited human rationality and paradigm of nonlinear processes. We believe that inertial properties of real estate markets are best revealed during short-term, sudden changes of structural origin, while during long-term evolution stages transition rates are slow enough for these systems to remain near to equilibrium. We suggest to treat the housing markets as complex [22], non-linear, dynamic [23] and open systems which evolve between [24] various equilibrium states.

This study is aimed at searching an analogy between the evolution of housing prices and hydrodynamic phenomena accompanying the movement of bodies in the incompressible fluid. Proposed in this paper description of the dynamics of housing prices as an analogy to the Reynolds number, has met only limited number of similar works in this field. Among others, the so-called stock market Reynolds number was developed by Antoniewicz and Juzwiszyn [25]. Thus, the aim of the article is to develop an equivalent of the Reynolds number (eReHM) for its implementation in the dynamical analysis of housing prices. The study concerns time series of housing (dwellings) prices from 2001 to 2017 recorded in north-eastern part of Poland (city Olsztyn).

\section{The analogy between the evolution of housing prices and hydrodynamic phenomena}

According to the mainstream economy, sudden, unusual and unexpected phenomena are usually treated as an extraordinary deviation from the current long-term trends, which the market mechanism will be able to deal with perfectly. Such phenomena were observed in Poland in the years 2006-2007, when there were sudden increases in property prices, followed by steady falls in the years 2008-2017. The main source of longterm stable declines in housing prices arises from the consequences of the international financial crisis (2007-2008) when the access to financing sources was restricted, the uncertainty of employment

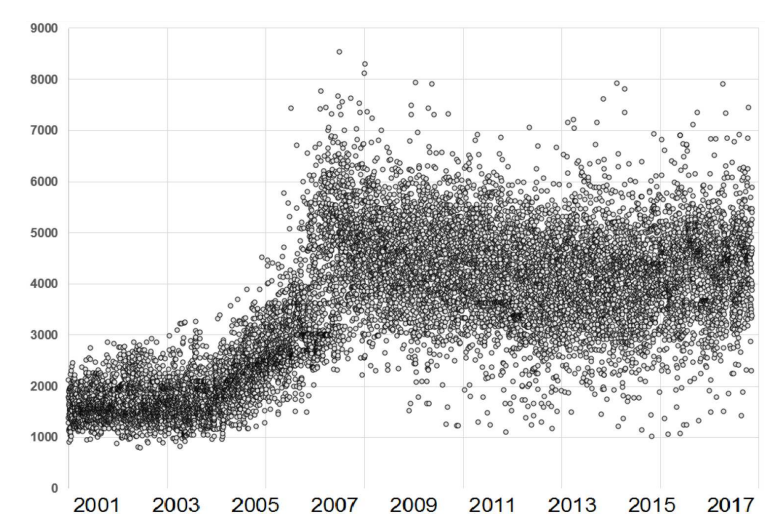

Fig. 1. Scatter plot of housing prices (dwellings) in the period from January 2001 until December 2017 in Olsztyn.

and long-term maintenance of high incomes increased, and the investment opportunities for the wealthy section of society relatively decreased.

The idea of searching an analogy between the evolution of housing prices and hydrodynamic phenomena arose from the observation of price dispersions of 12 thousand transactional housing prices (dwellings) in the period from 2001 until 2017 in Olsztyn (north-eastern part of Poland) presented in Fig. 1.

In the first period, from 2001 to 2005 (Fig. 1), slow increase in housing prices was observed (around $4-5 \%$ per month). Then, the increase was sharper until 2006 (from $10 \%$ to $15 \%$ per month, so over $120 \%$ per year). Such an unprecedented rise has not been registered since 1989 year (the onset for the polish housing market as a part of the market economy). Since December 2007 till December 2017 , housing prices gradually fall down at the rate from $0.5 \%$ to $1 \%$ per month. Figure 1 clearly shows morphological disproportions in the distribution of housing prices in particular sub-periods of 2001-2017. In the initial phase (2001-2007) a slight price stratification (min-max) is observed and its level does not change despite price increases in 2004-2007. A significant disruption of the current price evolution, combined with a rapid price increase, took place in 2007. This can be identified with the release and spillage of liquid from the previous regulated river course and the passage to unregulated river banks. Such an understanding of the price dispersion (Fig. 1) was the basis for searching an indicator of different levels of housing price dynamics. It refers directly to the thought of Alfred Marshall, who believed that economic laws do not resemble simple and precise gravity laws, but they seem to be more similar to complex and more difficult to predict — rights of fluid flow.

According to hydrodynamics, regular flow (idealistic phenomenon) occurs when the particles move steadily along the channel so that the current lines remain parallel to each other [26]. Any irregularities introduce disturbances and turn such an ideal 
liquid flow into a stable flow, also known as laminar flow. The increase in fluid velocity changes the character of this motion and generates chaotic and unpredictable eddy currents referred to as the turbulence [15]. Flows of fluids through various media are described by Navier-Stokes equations [27, 28]. In 1883, English scientist Osborne Reynolds published approximate solution to that problem and demonstrated that a given fluid flow might be described using a dimensionless number, today referred to as the Reynolds number [29].

Reynolds number Re is the ratio of inertial to viscous forces acting on a body moving relative to a fluid:

$$
\operatorname{Re}=\frac{L V}{\mu},
$$

where $L$ is a characteristics linear dimension (channel width), $V$ means flow velocity, and $\mu$ is kinematic viscosity of the fluid. In hydrodynamics, the Reynolds number is used to determine transitions between flow regimes on a spectrum from laminar to turbulent dynamics. Note, however, that the above formula needs re-defining to study the dynamics of any housing market, and the equivalence principle might be established in terms of stable and unstable price changes. From this point of view, it is justified to make use of certain measures of the dynamics of housing prices shown in Fig. 1 including, for example: price range, monthly-averaged volume of transactions and absolute month-to-month change in transactional price. In this study, it is assumed that the equivalent Reynolds number, which we called pseudo-Reynolds number for the housing market is given as:

$$
\mathrm{eReHM}=\frac{N S}{R},
$$

where $N$ is the number of transactions per month (value equivalent to $L$ ), $S$ is an absolute month-tomonth change in transactional price (value equivalent to $V$ ), and $R$ is the range of transactional prices (value equivalent to $\mu$ ).

\section{Results and Discussion}

The study was conducted in the city of Olsztyn, the north-eastern part of Poland. The city is currently inhabited by about 180,000 people in the area of almost $90 \mathrm{~km}^{2}$. The research used 12,000 housing (dwellings) prices in the range from January 2001 to December 2017. The source of data was the Real Estate Price and Value Register (RCiWN) maintained by the Olsztyn Municipal Office.

In the beginning, original data from Fig. 1 were processed into series of monthly-averaged transactional prices and absolute month-to-month changes in transactional prices, presented in Fig. 2.

Figure 2 clearly shows two levels of stationary prices: about PLN 1,800 per sqm (EUR 450) and about PLN 4,500 per sqm (EUR 1,500). Apart from that, there was unprecedented sharp increase in prices (120\% per annum) observed between 2006
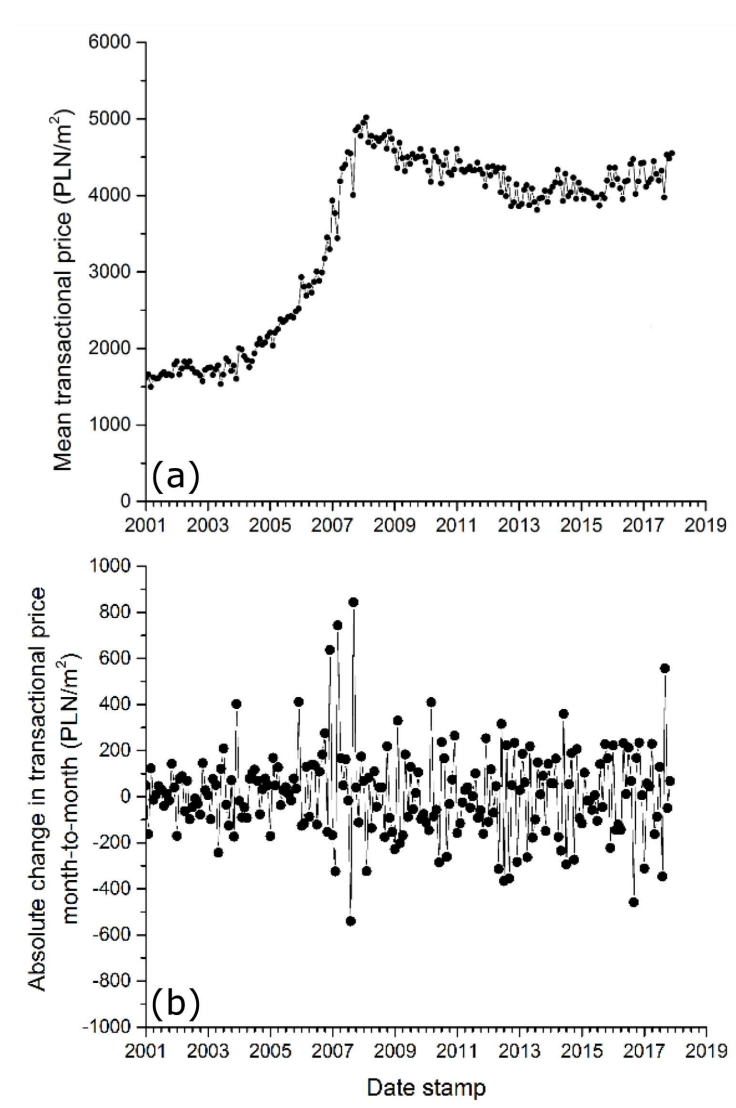

Fig. 2. Selected characteristics of time series of housing prices in Olsztyn (2001-2017): monthlyaveraged transactional prices (a), absolute monthto-month change in transactional price (b).

and 2007. There has been no such rapid rise in housing prices in Poland since 1989, i.e., since the market economy has been introduced. A number of transactions per month and a range of transactional prices are presented in Fig. 3. Month-to-month absolute change in transactional prices is a measure of the dynamics of this market indicating the velocity of price changes in time units. Therefore, we have taken this indicator as an equivalent of the mean flow velocity $V$.

As seen in Fig. 3, the smallest number of price transaction per month was found between 2004 and 2005, although large fluctuations turned out between 2006 and 2007 and later on from 2015. The number of real estate purchase/sale transactions in these intervals can be taken as a measure of the activity of the market. The lower the number of transcriptions in a given month, the greater the impact of a few transcriptions on the monthly average. In classical model, the linear dimension (channel width) $L$ sets the boundaries of fluid movement. Likewise, a number of price transactions in pseudo-Reynolds number for housing market limits the market, but due to its specific aspects it varies with elapsed time. We believe that this ratio may be a good equivalent of characteristics linear dimension (channel width) $L$. 
TABLE I
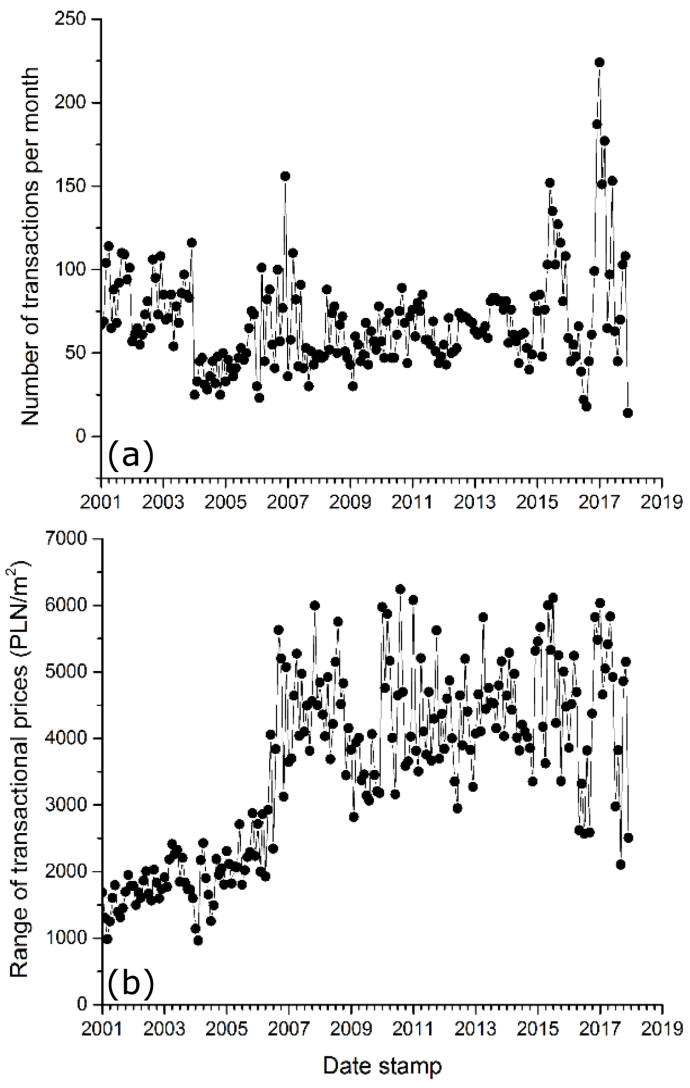

Fig. 3. Selected characteristics of time series of housing prices in Olsztyn (2001-2017): the number of transactions per month (a), the range of transactional prices (b).

It can be seen that during the stable evolution of the system, the range of prices approaches PLN 2,000 (EUR 500) per sqm and almost doubles in the beginning of the turbulent phase remaining at the level of PLN 4,000 (EUR 1,000) per sqm. We believe that this ratio may be a good equivalent of characteristics kinematic viscosity of the fluid $\mu$. The kinematic viscosity of the fluid is a measure of the resistance relative to dynamic loads or viscosity of a given fluid. The higher the viscosity, the larger internal drag force within the fluid. Figure 1 exhibits higher density of prices corresponding to their constrained fluctuations between 2001 and 2007. Accordingly, in the period from 2008 to 2017 the kinematic viscosity of the prices decreases resulting in significant price variations (low price density).

Measures of the dynamics of housing prices shown in Fig. 2 and Fig. 3 (absolute month-to-month change in transactional price, monthly-averaged volume of transactions and price range) significantly vary with elapsed time, because sub-series of transactional prices averaged over shorter time intervals remain independent of each other. Such a peculiarity makes the housing market completely different from the financial markets. In order to diminish seasonal and random fluctuations within selected
Statistical descriptors of the smoothed time-series 2001:01-2017:12

\begin{tabular}{l|c|c|c}
\hline \hline & $\begin{array}{c}\text { Range of } \\
\text { transactional } \\
\text { prices (FFT) }\end{array}$ & $\begin{array}{c}\text { Absolute change } \\
\text { in transactional } \\
\text { price (FFT) }\end{array}$ & $\begin{array}{c}\text { Number of } \\
\text { transactions } \\
\text { (FFT) }\end{array}$ \\
\hline$N_{\text {total }}$ & 204.00 & 203 & 204.00 \\
mean & 3562.71 & 13.27747 & 68.52 \\
std. dev. & 1156.06 & 27.41763 & 13.14 \\
SE of mean & 80.94 & 1.92434 & 0.92 \\
variance & 1336478.96 & 751.72646 & 172.66 \\
skewness & -0.81 & 1.39673 & 0.22 \\
kurtosis & -1.16 & 1.03215 & -0.63 \\
deviation & 1042.65 & 20.76049 & 10.74 \\
minimum & 1447.02 & -16.06024 & 42.55 \\
median & 4246.64 & 5.04017 & 66.58 \\
variance & 1336478.96 & 751.72646 & 172.66
\end{tabular}

TABLE II

Coefficients of the linear correlation of the smoothed time-series.

\begin{tabular}{c|c|c}
\hline \hline $\begin{array}{c}\text { Range of } \\
\text { transactional } \\
\text { prices (FFT) }\end{array}$ & $\begin{array}{c}\text { Absolute change } \\
\text { in transactional } \\
\text { price (FFT) }\end{array}$ & $\begin{array}{c}\text { Number of } \\
\text { transactions } \\
(\mathrm{FFT})\end{array}$ \\
\hline 1.0000 & -0.1765 & 0.0745 \\
- & 1.0000 & -0.1687 \\
- & - & 1.0000
\end{tabular}

quantities, smoothing procedure was carried out. Thanks to that, primary noise of raw prices can be substantially reduced leaving basic trends untouched, but more homogeneous between time intervals. The smoothing procedure was done using 12-point Fast Fourier Transform (FFT) with 0.04166 cutoff frequency. Table I summarizes basic statistics of the smoothed time-series (2001-2017). Table II presents coefficients of the linear correlation of the smoothed time-series.

At a significance level below 0.05, the hypothesis of correlation between the variables studied was rejected. Smoothed time-series of averaged transaction prices, absolute changes in transactional price, numbers of transactions and ranges of transactional prices, are presented in Fig. 4.

Time-dependent plot of the pseudo-Reynolds number for housing prices calculated according to $(2)$ is presented in Fig. 5.

As a result of the research of evolution of house prices in Olsztyn in 2001-2017 the three phases were defined:

[A] stable evolution of the housing market equivalent to laminar flow $(|\mathrm{eReHM}| \leq 0.5)$

[B] transitional evolution of the housing market - equivalent to disturbed flow, namely $0.5>|\mathrm{eReHM}| \leq 1$

[C] unstable, structural change of the housing market - equivalent to turbulent flow, namely $|\mathrm{eReHM}|>1$. 

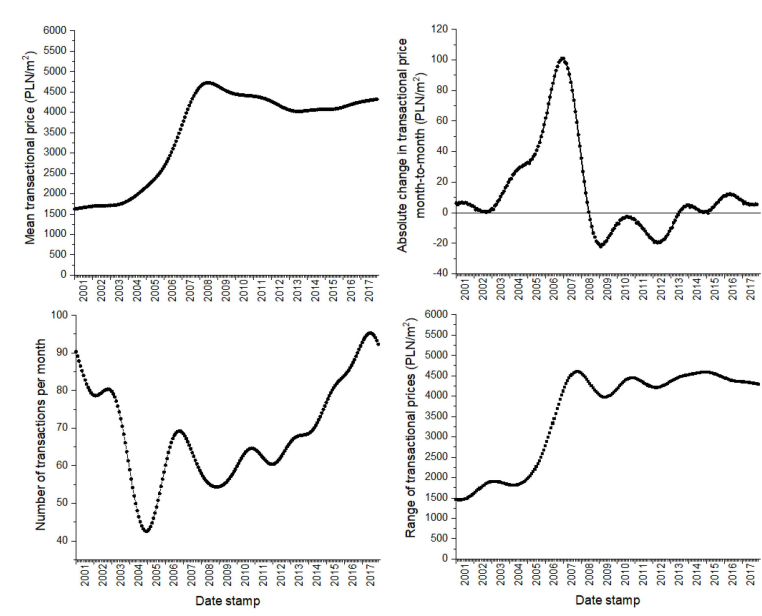

Fig. 4. Selected characteristics of FFT smoothed time series of housing prices in Olsztyn (2001-2017).

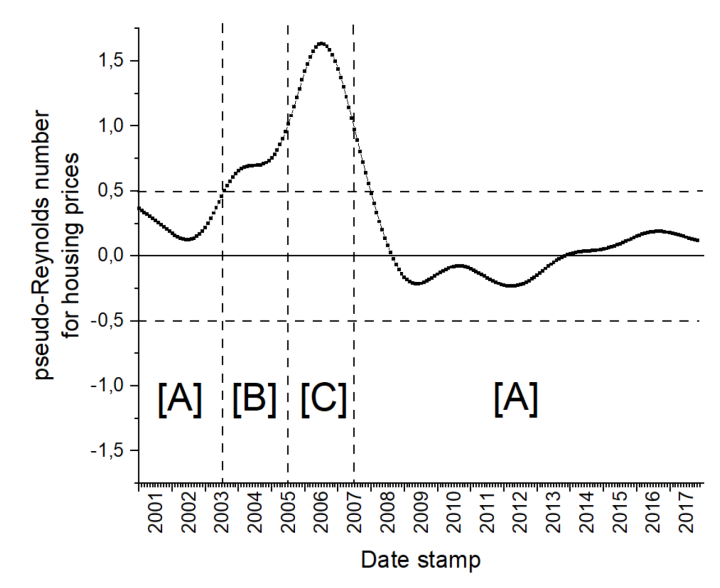

Fig. 5. Equivalent of the Reynolds number for the housing market in Olsztyn in the period from January 2001 till December 2017.

We believe that exceeding the limits of pseudoReynolds number for the housing market, eReHM indicates that the price dynamics of dwellings has reached a critical point. In this sense, when $|\mathrm{eReHM}| \leq 0.5$ there is laminar housing price dynamics, $0.5>|\mathrm{eReHM}| \leq 1$ there is unstable housing price dynamics, and for $|\mathrm{eReHM}|>1$ there is turbulent housing price dynamics.

\section{Conclusions}

Since hydrodynamics phenomena appear significantly different from those related to the housing market, it might be hardly possible to find out the straight equivalence of dimensionless Reynolds number within the series of housing prices. Having hydrodynamic relation for Re that includes linear channel size, mean flow velocity and kinematic viscosity of the fluid, presented work was aimed at establishing analogous measure of the stability of trends in housing prices using the term: pseudoReynolds number or Reynolds number equivalent
(eReHM) for housing market. Common factors in these two pictures are: (1) short-range sharp changes in some quantities (turbulence $=$ market bubble), and (2) long-term slow fluctuations (laminar $=$ market development). Actually, the reason behind observed evolution of the housing prices from 2001 to 2017 was out of the scope of this work, because it is widely discussed elsewhere. Sharp changes in housing prices in Olsztyn between 2005 and 2006 are correlated with those observed on other housing markets in Poland. External stimuli appear to have detrimental effect on the stability of the housing market resulting in reduction of the number of transactions (uncertainty as to the prospective benefits for the sellers, increased pressure from the buyers), followed by asymptotic transition towards new equilibrium state. In that time, however, the number of transactions remained relatively low, which might be a sign of excessive contribution of the speculation. Before and after that time, the number of transactions substantially increases (lower speculation contribution).

Presented in this paper equivalent Reynolds number (eReHM), expressed in terms of the range of transactional prices, absolute month-to-month change in transactional prices and number of transactions per month, can be applied as a warning indicator of instability on housing markets. While in hydrodynamic there is the threshold in always positive Re numbers that delimits laminar flow the turbulent one, however some parameters might become negative locally (flow velocity, for example) even though the average velocity remains larger than zero. On the other hand, equivalent Re value for housing markets might be negative, because critical transition might occur as a result of sharp increase (as in presented case study) as well as the collapse in housing prices. Here, monthly absolute change in transactional price (equivalent to flow velocity) in the range from 2008 to 2013 goes below zero, but beyond that period the housing markets no longer suffer from crises.

We believe that the determination of the thresholds for pseudo-Reynolds number for other local housing market and their later analysis may contribute to an increase in market predictability.

\section{References}

[1] M. Ball, Housing policy and economic power: the political economy of owner occupation Routledge, London 1983.

[2] D. Andrews, A.C Sánchez, OECD Economics Department Working Papers No. 849 (2011).

[3] G. Galster, Urban Stud. 33, 1797 (1996).

[4] A. Beltratti, C. Morana, J. Bank. Finance 34, 533 (2010).

[5] D.E Orenstein, S.P Hamburg, Popul. Environ. 31, 223 (2010). 
[6] S. Czaja, Prace Naukowe Akademii Ekonomicznej we Wrocławiu, Seria: Monografie i Opracowania (nr 100) 1997, 200 (1997) (in Polish).

[7] J. Unold, Prace Naukowe Akademii Ekonomicznej we Wrockawiu, Seria: Monografie $i$ Opracowania (nr 100) 1997, 252 (2003) (in Polish).

[8] F. Capra, U. Mattei, The Ecology of Law: Toward a Legal System in Tune with $\mathrm{Na}$ ture, Community, Berrett-Koehler Publishers, 2015.

[9] V. Acharya, T. Philippon, M. Richardson, N. Roubini, Financ. Mark. Inst. Instrum. 1889 (2009).

[10] P. Ashton, Environ. Plan. A 411420 (2009).

[11] N. Roubini, S. Mihm, Crisis economics: A Crash Course in the Future of Finance Penguin, 2010.

[12] Y. Demyanyk, O. Van Hemert, Rev. Financ. Stud. 24, 1848 (2011).

[13] D. Colander, R. Holt, B. Rosser Jr, Rev. Polit. Econ. 16, 485 (2004).

[14] A. Jakimowicz, J. Juzwiszyn, Acta Phys. Pol. A 127, A-78 (2015).

[15] A. Jakimowicz, in: Chaos and Complex Systems, Eds. S. Stavrinides, S. Banerjee, S. Caglar, M. Ozer, Springer, Heidelberg 2013, p. 395.

[16] G. Zhang, P. Qian, Z. Su, Chaos Solitons Fractals 128219 (2019).

[17] S. Battiston, J.D. Farmer, A. Flache, D. Garlaschelli, A.G. Haldane, H. Heesterbeek, C. Hommes, C. Jaeger, R. May, M. Scheffer, Science 351, 818 (2016).
[18] D. Stamovlasis, in: Complex Dynamical Systems in Education, Eds. M. Koopmans, D. Stamovlasis, Springer, Cham 2016, p. 141.

[19] J. Brzezicka, R. Wisniewski, M. Figurska, Land Use Policy 78, 515 (2018).

[20] L. Kristoufek, Adv. Complex Syst. 15. 1250065 (2012).

[21] B.W. Arthur, S.N. Durlauf, D. Lane, The Economy as an Evolving Complex System II, Addison-Wesley, Reading (MA) 1997.

[22] M. Bełej, S. Kulesza, Acta Phys. Pol. A 123, 1351 (2013).

[23] S. Kulesza, M. Bełej, Acta Phys. Pol. A 127, A-99 (2015).

[24] R. Dieci, F. Westerhoff, J. Econ. Dyn. Control 71, 21 (2016).

[25] J. Juzwiszyn, A. Krzywicki, Prace Naukowe Akademii Ekonomicznej we Wrocławiu, 2006, 69 (2006) (in Polish).

[26] M. Tempczyk, Teoria Chaosu dla Odważnych, Wyd. Nauk. PWN, Warszawa 2002 (in Polish).

[27] A.J. Chorin, Math. Comput. 22, 745 (1968).

[28] G.E Karniadakis, M. Israeli, S.A. Orszag, J. Comput. Phys. 97, 414 (1991).

[29] J. Happel, H. Brenner, Low Reynolds Number Hydrodynamics, Springer Science \& Business Media, 2012. 